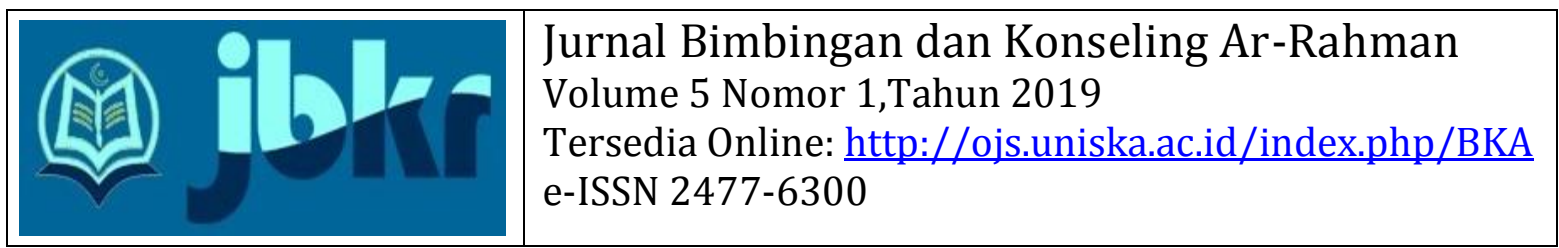

\title{
HUBUNGAN ANTARA CITRA TUBUH DENGAN HARGA DIRI PADA SISWI KELAS X PEMASARAN (PM) DI SMK NEGERI 1 SALATIGA
}

\author{
Shinta Widya Ratri ${ }^{1}$, Tritjahjo Danny Soesilo ${ }^{2}$, Setyorini ${ }^{3}$ \\ Program Studi Bimbingan dan Konseling FKIP-Universitas Kristen Satya Wacana,Jl. Diponegoro No 52-60 \\ Salatiga - Indonesia 50711 \\ ${ }^{1} 132015042 @$ student.uksw.edu \\ ${ }^{2}$ tritjahjo.danny@uksw.edu \\ ${ }^{3}$ seyorini@staff.uksw.edu
}

\begin{abstract}
ABSTRAK
Penelitian ini bertujuan untuk mengetahui Hubungan antara citra tubuh dengan harga diri pada siswi kelas $\mathrm{X}$ Pemasaran (PM) di SMK Negeri 1 Salatiga. hipotesisi yang diajukan dalam penelitian ini adalah ada hubungan yang signifikan anatara citra tubuh dengan harga diri pada sisiwi kelas X Pemasaran (PM) di SMK Negeri 1 Salatiga. Subjek dalam penelitian ini adalah siswi kelas X Pemasaran (PM) di SMK Negeri 1 Salatiga yang berjumlah 67 siswi. Pengumpluan data menggunakan skala citra tubuh yang dikemukakan oleh Cash (2000) dalam Multidimensional Body Self Relation Questionnaire : Appearance Scale (MBSRQ-AS) dengan jumlah item 52 pernyataan dan skala harga diri oleh Rosenberg (2002) dalam Self-Esteem Scale (SEC) dengan jumlah item 28 pernyataan. Pendakatan penelitian ini adalah kuantitatif korelasional dengan tenik korelasi kendall's tau$b$. Hasil penelitian ini menunjukkan koefisien korelasi $\mathrm{r}=0.137$ dengan signifikan $0.230>0.05$, maka dapat dinyatakan bahwa tidak ada hubungan yang signifikan antara citra tubuh dengan harga diri pada siswi kelas $\mathrm{X}$ Pemasaran (PM) di SMK Negeri 1 Salatiga. Dengan demikian hipotesis yang diajukan ditolak. Hal ini berarti bahwa citra tubuh tidak memiliki hubungan yang signifikan dengan harga diri siswi SMK Negeri 1 Salatiga.
\end{abstract}

Kata kunci: Citra Tubuh; Harga Diri

\section{ABSTRACT}

This study aims to determine the relationship between body image and self-esteem in class X Pemasaran (PM) at SMK Negeri 1 Salatiga. The hypothesis proposed in this study is that there is a significant relationship between body image and self-esteem on the side of class X Pemasaran (PM) at SMK Negeri 1 Salatiga. The subjects in this study were students of class X Pemasaran (PM) at SMK Negeri 1 Salatiga, amounting to 67 students. Data collection uses the body image scale proposed by Cash (2000) in the Multidimensional Body Self Relation Questionnaire: Appearance Scale (MBSRQ-AS) with the item 52 statements and self-esteem scale by Rosenberg (2002) in the Self-Esteem Scale (SEC) with item number 10 statement. The approach of this study is quantitative correlational with correlation analysis of Kendall's tau-b. The results of this study indicate that the correlation coefficient $r=0.137$ with a significant 0.230>0.05, it can be stated that there is no significant relationship between body image and self-esteem in the class X Pemasaran (PM) at SMK Negeri 1 Salatiga. Thus the proposed hypothesis is rejected.

Keywords: Body Image;Self-Esteem

Dipublikasikan Oleh :

UPT Publikasi dan Pengelolaan Jurnal

Universitas Islam Kalimantan Muhammad Arsyad Al-Banjari Banjarmasin 


\section{PENDAHULUAN}

Tahun 2019 media massa sedang diramaikan dengan para gadis yang merubah dirinya menjadi seperti boneka Barbie. Trend masa kini adalah remaja mulai merubah bagian-bagian wajah mereka dengan melakukan sulam alis, sulam bibir, tanam bulu mata dan memutihkan gigi. Perkembangan keadaan fisik sering menimbulkan perasaan resah oleh remaja (Setyaningsih, 2013). Usia remaja merupakan golongan usia yang sangat peduli terhadap keadaan tubuhnya (Kitri, 2017). Survey yang telah dilakukan menunjukan bahwa tingkat kepuasan remaja putri terhadap tubuhnya lebih rendah dibandingkan dengan remaja putra. Hal tersebut dapat dibuktikan melalui survei yang di lakukan oleh American Association of Univercity (Huebscher dalam Setyaningsih, 2013) yang mengatakan bahwa hanya $29 \%$ remaja putri yang merasa puas tehadap tubuhnya dan $50 \%$ dari remaja putra merasa baik-baik saja terhadap tubuh mereka. Family Health Study menemukan bahwa perempuan mengalami penurunan harga diri pada usia 12 tahun sampai 17 tahun (Baldwin \& Hoffman dalam Santrock, 2007)

Menurut Schilder (dalam Bell dan Rushforth, 2008), citra tubuh adalah gambaran tentang tubuh seseorang yang terbentuk dalam pikiran individu itu sendiri. Arthur (Ridha, 2012) imajinasi subjektif yang dimiliki seseorang tentang tubuhnya dan seberapa baik tubuhnya menyesuaikan persepsi-persepsi orang lain terhadap tubuhnya. Remaja sering merasa tidak puas terhadap keadaan fisiknya karena seseorang menilai atas tubuhnya dengan memberikan penilaian berupa penilaian positif dan negatif. Tidak puasnya seseorang terhadap tubuhnya dapat memicu munculnya gangguan pada psikologis remaja. Para remaja kerap merasa tidak puas terhadap apa yang telah dimilikinya. Ketidak puasan remaja bertentangan dengan tugas perkembangan menurut Hurlock (dalam Setyaningsih, 2013) yang menyatakan bahwa "salah satu tugas pekembangan remaja adalah menerima keadaan fisik dan menggunakan tubuhnya secara efektif. Sejalan dengan pendapat Havighurts (dalam Padmomartono, 2014) bahwa "secara spesifik pekembangan remaja yaitu mencapai kematangan fisik dan mendayagunakan tubuhnya secara efektif'.

Jika remaja merasa tidak puas dengan tubuhnya apa adanya akan mengakibatkan seorang remaja sulit menilai dan menghargai dirinya seutuhnya. Maka masalah dan ketidakbahagiaan akan mudah timbul pada masa remaja. Seperti pendapat Astri (2002) bahwa "orang yang memutuskan untuk menjadi dirinya sendiri, maka dia akan lebih santai dalam menjalani kehidupannya dan tidak merasa terbebani karena tidak ada satupun yang disembunyikan". Sehingga membuat remaja cenderung mempertahankan gambaran diri yang palsu dan menyimpang. Remaja putri tidak hanya memberi penilaian terhadap tubuhnya namun juga perlu memberikan penilaian akan dirinya. Harga diri (selfesteem) merupakan taraf atau derajat seseorang menilai dirinya sendiri (Reber \& Reber, 2010). Harga diri tidak berhubungan dengan kehebatan yang dimiliki, namun seberapa berharganya diri yang dimiliki. Kaitannya citra tubuh dengan harga diri seperti yang diungkapkan oleh Burn (dalam Dahlia, 2012) yang mengemukakan terdapat lima faktor yang mempengaruhi harga diri yaitu pengalaman, pola asuh, lingkungan, sosial ekonomi, dan citra tubuh.

Observasi awal yang telah peneliti lakukan pada salah satu kelas X PM di SMK Negeri 1 Salatiga diperoleh hasil bahwa 14dari jumlah siswi dalam 1 kelas yaitu 31 merasa tidak puas dengan tubuh mereka. Setelah ditanya mereka mengaku bahwa memiliki rambut yang ikal dan berantakan, warna kulit hitam, hidung pesek, tubuh tidak ideal, dan jerawatan. Mereka telah berupaya untuk memperbaiki tubuh agar lebih menarik dan memiliki kepuasan terhadap tubuhnya. Hal tersebut dapat dilihat dari beberapa siswa yang merubah penampilannya, seperti melakukan perawatan skincare, diet ketat dan rebonding rambut.

Penelitian yang dilakukan oleh Tsamarah (2018) yang meneliti tentang hubungan antara citra tubuh dengan harga diri pada siswi SMA Kesatrian Semarang menunjukkan bahwa adanya hubungan signifikan antara citra tubuh dengan harga diri ditunjukkan dengan nilai koefisien korelasi rxy sebesar 0,233 dengan $p$ value $=0,002<0,01$. Cadrasari (2003) melakukan penelitian mengenai hubungan antara citra tubuh dengan harga diri pada remaja putri kelas II di SMPK Santo Carolus Surabaya. Hasil penelitian menunjukkan bahwa ada hubungan yang signifikan antara citra tubuh dengan harga diri, yaitu dengan $\mathrm{rxy}=0,476, \mathrm{p}=0,000(\mathrm{p}<0,05)$.

SedangkanIlahi (2014) melakukan sebuah penelitian dengan judul hubungan antara citra tubuh dengan harga diri remaja perempuan pada komunitas gym di Azkar Gym Masaran Sragen, diperoleh hasil bahwa tidak ada hubungan yang signifikan antara citra tubuh dengan harga diri pada komunitas gym ditunjukkan dengan $\mathrm{r}_{\mathrm{xy}}=0,029$ dengan nilai signifikansi $0,873(\mathrm{p}>0,01)$.

Berdasarkan hasil observasi dan riset isue di atas maka peneliti tertarik untuk mengadakan penelitian ulang dengan judul yang sama yaitu hubungan antara citra tubuh dengan harga diri pada siswi kelas $\mathrm{X}$ Pemasaran (PM) di SMK Negeri 1 Salatiga. Penelitian ini bertujuan untuk mengetahui signifikansi hubungan antara citra tubuh dengan harga diri pada siswi kelas $\mathrm{X}$ Pemasaran (PM) di SMK Negeri 1 Salatiga.

Rosenberg (Mruk, 2006) mendefinisikan bahwa harga diri merupakan sikap yang dilihat berdasarkan 
pada persepsi mengenai nilai seseorang terhadap dirinya sendiri berupa harga diri tinggi atau harga diri rendah. Harga diri tinggi mengungkapkan perasaaan seseorang bahwa seseorang merasa cukup baik. Individu merasa bahwa dirinya berharga, dia menghargai dirinya sendiri tapi tidak kagum pada dirinya dan tidak berharap orang lain kagum ada dirinya. Individu tidak perlu menganggap bahwa dirinya sendiri lebih unggul dari orang lain. Harga diri merupakan salah satu aspek mental yang mempengaruhi emosi seorang remaja, oleh karena itu harga diri yang tinggi perlu dibentuk sejak kecil. Jika seseorang memiliki harga diri yang tinggi maka dapat menjalani kehidupan dengan baik dan dapat berkembang dengan optimal. Pembentukan harga diri dapat terhambat ketika seseorang tidak berani mengahadapi kenyataan hidup yang tidak sesuai dengan harapannya. Selain itu ketika seseorang merasa bersalah terhadap pelanggaran yang pernah dilakukan sehingga tidak memiliki keyakinan terhadap dirinya sendiri dan tidak dapat menentukan apa yang baik dan buruk bagi dirinya.

Terdapat dua aspek dalam dalam pengukuran harga diri menurut Rosenberg (Tafarodi \& Milne, 2002) yaitu, self competence yang meliputi merasa puas dengan kemampuan diri sendiri dan merasa memiliki kemampuan yang baik dan self liking dimana seseorang menilai dirinya baik atau buruk, memiliki kualitas yang aik dan memiliki sikap positif terhadap dirinya.

Menurut Cash dan Pruzinsky (Cash, 2000) citra tubuh adalah sikap seseorang terhadap tubuh yang dimilikinya berupa penilaian positif atau negatif terhadap atribut fisik, bisa dikatakan bahwa penampilan merupakan bagian utama dari penilaian diri. Penilaian positif pada citra tubuh seperti kepuasan pada bagian tubuh, kepuasan pada penampilan dan kepuasan pada bentuk tubuh yang dimiliki. Sedangkan penilaian negatif seperti kecemasan menjadi gemuk, kecemasan memiliki penampilan buruk dan kecemasan pada bagian tubuh yang tidak ideal. Ketika seseorang dapat menganggap tubuhnya baik dan sempurna maka dapat disebut memiliki citra tubuh yang positif, sebaliknya ketika seseorang menganggap tubuhnya buruk dan tidak sempurna maka dapat dikatakan memiliki citra tubuh yang negatif. Citra tubuh bukan hanya sekedar penilaian terhadap fisik yang nampak tetapi juga penampilan yang ditunjukkan. Upaya untuk selalu

\section{HASIL DAN PEMBAHASAN Hasil Penelitian}

Penelitian ini dilakukan pada seluruh siswi kelas X Pemasaran yang berjumlah 67 orang siswi yang terdiri dari 36 orang siswi kelas X Pemasaran 1 memperbaiki penampilan menunjukkan bahwa penampilan merupakan hal paling penting dalam penilaian diri.

Cash dan Pruzinsky (Cash, 2000) mengemukakan ada lima aspek untuk mengukur citra tubuh, yaitu appearance evaluation (evaluasi penampilan), appearance orientation (orientasi penampilan), body area satisfaction (kepuasan terhadap bagian tubuh), overweight preoccupation (kecemasan menjadi gemuk) dan self-classified weight (pengkategorian ukuran tubuh)

Perkembangan citra tubuh itu sendiri dipengaruhi oleh beberapa faktor menurut Cash dan Pruzinsky (2002), yaitu sosialisasi kebudayaan, pengalamanpengalaman interpersonal, karakteristik fisik dan faktor kepribadian

Hipotesis yang diajukan dalam penelitian ini untuk diuji kebenarannya adalah ada hubungan yang signifikan antara citra tubuh dengan harga diri siswi kelas X Pemasaran (PM) di SMK N 1 Salatiga.

\section{METODE}

Jenis penelitian ini adalah penelitian korelasional, yaitu suatu penelitian yang bertujuan untuk membuktikan keeratan hubungan satu variable dengan variabel lainnya (Soesilo, 2018).Populasi penelitian ini adalah siswi SMK N 1 Salatiga kelas X Pemasaran (PM) sebanyak 67 orang siswi.Teknik pengambilan sampel adalah total sampling. Teknik pengumpulan data penelitian ini menggunakan skala citra tubuh dan skala harga diri. Teknik analisis data menggunakan teknik korelasi Kendall's Tau-b yang dibantu dengan program SPSS for Windows 20.0 Version.

Skala citra tubuh disusun berdasarkan aspek yang dikemukakan Multidemensional Body Self Relation Questionnaire: Appearance Scale (MBSRQAS) oleh Cash (2000). Hasil uji validitas item variabel citra tubuh terdapat 52 dari 57 item tergolong valid dengan rentang koefisien korelasi 0,207-0,814 dan koefisien reliabilitas $\alpha=0,921$. Terdapat 26 item favourable dan 26 item unfavourable.

Sedangkan skala harga diri ini disusun berdasarkan dua aspek dalam Self-Esteem Scale (SES) dari Rosenberg (Tafarodi \& Milne, 2002). Terdapat 5 item favourable dan 5 item unfavourable. Hasil uji validitas item variabel harga diri terdapat 10 item (keseluruhan) tergolong valid dengan rentang korelasi 0,421-0,813 dan hasil koefisian reliabilitas $\alpha=0,911$.

dan 31 orang siswi kelas X Pemasaran 2. Berdasarkan tabel 1 dapat diketahui bahwa siswi kelas $\mathrm{X}$ Pemasaran SMK Negeri 1 Salatiga dominan memiliki Citra Tubuh dengan kategori cukup tinggi dengan jumlah siswi sebanyak 38 dari total 67 siswi. 
Tabel 1. Daftar Distibusi Citra Tubuh

\begin{tabular}{llll}
\hline Kategori & Skor & Frekuensi & Presentase (\%) \\
\hline Sangat tinggi & $\geq 184$ & 1 & 1,5 \\
& & & 13,4 \\
Tinggi & $163-183$ & 9 & 56,8 \\
& & & 25,4 \\
Cukup Tinggi & $140-162$ & 38 & 2,9 \\
Sedang & $118-139$ & 17 & 0 \\
Rendah & $96-117$ & 2 & 0 \\
Cukup Rendah & $74-95$ & 0 & $\mathbf{1 0 0}$ \\
Sangat Rendah & $52-73$ & 0 & $\mathbf{6 7}$ \\
\hline
\end{tabular}

Tabel 2. Daftar Distibusi Harga Diri

\begin{tabular}{llll}
\hline Kategori & Skor & Frekuensi & Presentase (\%) \\
\hline Sangat tinggi & $\geq 40$ & 0 & 0 \\
Tinggi & $35-39$ & 2 & 2.9 \\
& $30-34$ & 25 & 37.4 \\
Cukup Tinggi & $25-29$ & 34 & 50.7 \\
Sedang & $20-24$ & 5 & 7.5 \\
Rendah & $15-19$ & 1 & 1.5 \\
Cukup Rendah & $10-14$ & 0 & 0 \\
Sangat Rendah & Total & $\mathbf{6 7}$ & $\mathbf{1 0 0}$ \\
\hline
\end{tabular}

Berdasarkan tabel 2 dapat diketahui bahwa siswi kelas X Pemasaran SMK Negeri 1 Salatiga dominan memiliki tingkat harga diri sedang dengan jumlah siswi sebanyak 34 dari total 67 siswi.

\section{Uji Hipotesis}

Uji hipotesis ini bertujuan untuk mengetahui ada atau tidak adanya hubungan antara citra tubuh dengan harga diri siswi kelas X Pemasaran di SMK Negeri 1 Salatiga.

Tabel 3. Analisis Korelasi antara Citra Tubuh dengan Harga Diri

\begin{tabular}{|c|c|c|c|c|}
\hline \multirow{2}{*}{ Kendall's tau_b } & \multirow{3}{*}{$\begin{array}{l}\text { Citra } \\
\text { Tubuh }\end{array}$} & \multirow{2}{*}{ Correlation } & \multirow[t]{2}{*}{ CitraTbh } & Harga Diri \\
\hline & & & & \\
\hline & & Coefficient & 1.000 & .157 \\
\hline & & Sig. (2-tailed) & . & .155 \\
\hline & & $\mathrm{N}$ & 67 & 67 \\
\hline & Harga & Correlation & .157 & 1.000 \\
\hline & Dir1 & $\begin{array}{l}\text { Coefficient } \\
\text { Sig (2-tailed) }\end{array}$ & 155 & \\
\hline & & $\mathrm{N}$ & 67 & 67 \\
\hline
\end{tabular}

Berdasarkan hasil uji korelasi diatas dapat diketahui bahwa hasilanalisiskorelasi antara citra tubuh dengan harga diri menghasilkan nilai koefisien korelasi ( $\mathrm{r}$ ) sebesar 0.157 dengan koefisien signifikansi $0,155>$ 0,05. maka hipotesis dalam penelitian ditolak.Karena hasil korelasi menunjukkan tidak ada hubungan yang signifikan maka analisis dilanjutkan antara sub Dipublikasikan Oleh :

UPT Publikasi dan Pengelolaan Jurnal

Universitas Islam Kalimantan Muhammad Arsyad Al-Banjari Banjarmasin variabel citra tubuh dengan harga diri yaitu variabel $\mathrm{X} 1, \mathrm{X} 2, \mathrm{X} 3, \mathrm{X} 4$, dan X5 dengan variabel Y. Hasil yang diperoleh adalah varibel $\mathrm{X} 1$ memiliki hubungan yang signifikan dengan variable $\mathrm{Y}$ ditunjukkan dengan nilai koefisien korelasi ( $\mathrm{r}$ ) sebesar 0,392 dengan koefisien signifikansi 0,001>0,05. 
Tabel 4. Analisis Korelasi Variabel X1 dengan Variabel Y

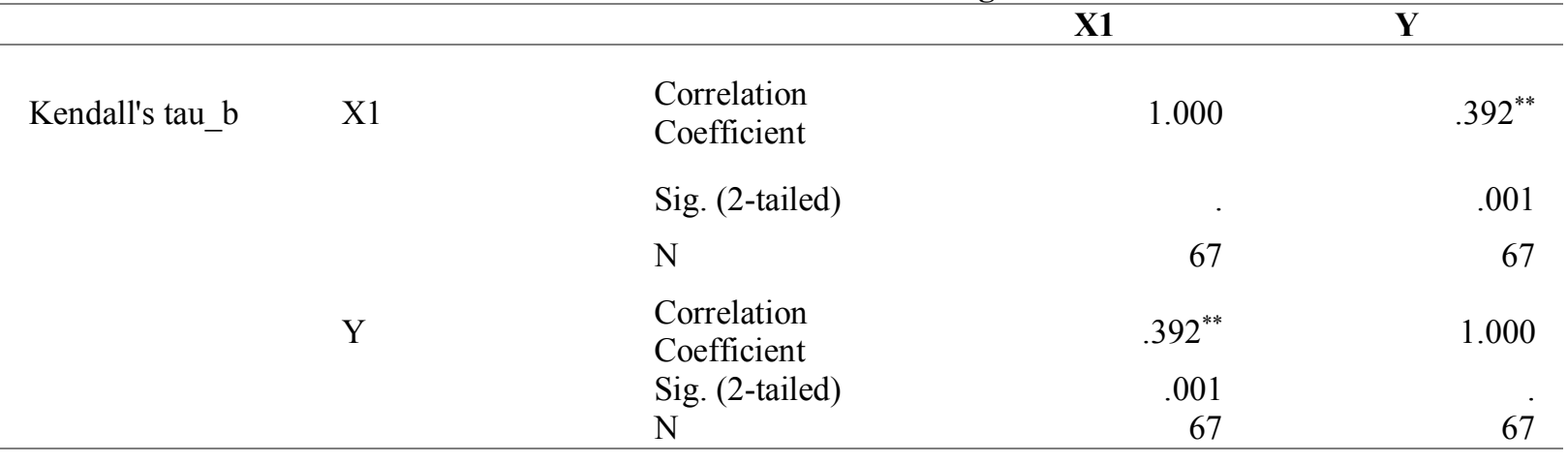

Berdasarkan hasil diatas dapat diketahui bahwa $\mathrm{r}=$ 0,392 dengan signifikansi seebesar 0,001 ( $\mathrm{p}<0,05)$.

\section{Pembahasan}

Berdasarkan hasil penelitain citra tubuh dengan harga diri pada siswi kelas X Pemasaran di SMK Negeri 1 Salatiga diperoleh hasil perhitungan korelasi sebesar $r_{x y}=0,157$ dengan signifikansi sebesar 0,155 ( $p>0,05$ ). Hal ini menunjukkan bahwa hipotesis penelitian ditolak maka tidak ada hubungan antara citra tubuh dengan harga diri pada siswi kelas X Pemasaran di SMK Negeri 1 Salatiga.

Hasil penelitian ini tentu tidak mendukung pendapat yang dikemukakan oleh Fianinda (2017) bahwa remaja dengan citra tubuh yang buruk maka ia akan mengalami penurunan harga diri.Orth, dkk (Siti, 2017) juga berpendapat bahwa harga diri dipengaruhi oleh faktor status sosial ekonomi (tingkat pendidikan, pendapatan dan tingkat jabatan) selain itu faktor demografi(usia, jenis kelamin, dan suku dri individu) juga mempengaruhi harga diri.Dengan hasil penelitian ini yang menyatakan bahwa tidak ada hubungan yang signifikan antara citra tubuh dengan harga diri dikarenakan harga diri remaja bisa saja dipengaruhi oleh hal lain seperti misalnya tingkat pendidikan, keadaan sosial ekonomi keluarga atau pola asuh orang tua. Harga diri dibawa sejak lahir namun seiring dengan perkembangan manusia harga diri dapat dibentuk menuju harga diri yang tinggi atau rendah.

Berdasarkan daftar distribusi siswi kelas $\mathrm{X}$ Pemasaran di SMK Negeri 1 Salatiga diketahui bahwa citra tubuh memiliki skor paling banyak sebesar $56.8 \%$ yang berada pada kategori cukup tinggi dan harga diri memiliki skor paling banyak 50.2\% diketegori sedang. Citra tubuh siswi kelas $\mathrm{X}$ Pemasaran di SMK Negeri 1 Salatiga berada pada kategori cukup tinggi karena mereka dapat diterima di lingkungannya dengan baik meskipun mereka memiliki bentuk tubuh, warna kulit dan lainnya yang berbeda dari lingkungan sekitarnya. Selain itu siswi kelas X Pemasaran di SMK Negeri 1 Salatiga juga dapat menerima dan menghargai keadaan dirinya sendiri. Menurut Tailor (Fretes, 2014) penerimaan merupakan kemampuanberhubungan dengan orang lain tanpa mengendalikan dan menilai.

Remaja pada usia sekolah menengah merupakan fase mencari identitas diri. Pada masa remaja identitas diri yang dicari berupa usaha untuk menjelaskan siapa dirinya, apa peranannya dalam masyarakat, serta menunjukkan dirinya dengan menggunakan barangbarang yang menonjol agar remaja merasa menarik dan dipandang ada oleh orang lain (Hurlock, 1980). Maka seorang remaja perlu memiliki sikap positif terhadap diri sendiri. Dari hasil penelitian yang menunjukkan citra tubuh dan harga diri yang cukup tinggi, salah satunya disebabkan oleh kepercyaan diri yang baik yang dimiliki oleh siswi kelas X Pemasaran di SMK Negeri 1 Salatiga. Menurut Maslow (Fretes, 2014) percaya diri merupakan modal dasar untuk mengembangkan atau aktualisasi diri, dengan percaya diri seseorang akan mampu mengenal dan memahami diri sendiri.

Mental seseorang terbentuk tidak dipengaruhi oleh aspek fisik. Salah satu aspek mental yaitu harga diri.Aspek fisik seseorang tidak berpengaruh pada bagaimana seseorang menghargai dirinya sendiri.Aspek fisik yang dimaksud seperti bentuk tubuh, warna rambut, tinggi badan, warna kulit dan struktur wajah.Seseorang yang memiliki fisik yang kurang sempurna tetap memiliki harga diri yang tinggi dan tetap menghargai dirinya sendiri meskipun ada kekurangan pada fisik.Harga diri seseorang dapat terhambat jika tidak dapat menghadapi kenyataan yang ada dan menganggap negatif dirinya.Secara umum apabila seseorang telah memiliki harga diri yang tinggi maka apapun yang terjadi pada tubuhnya tidak akan menurunkan harga diri yang telah dimiliki.

Hasil penelitian yang menyatakan bahwa tidak ada hubungan yang signifikan antara citra tubuh dengan harga diri pada siswi kelas X Pemasaran di

Dipublikasikan Oleh : 
SMK Negeri 1 Salatiga peneliti mengkorelasikan antara aspek variabel $\mathrm{X}$ dengan variable $\mathrm{Y}$. Setelah dilakukan analisis lebih dalam melalui aspek citra tubuh, ditemukan bahwa salah satu aspek citra tubuh memiliki hubungan yang signifikan dengan harga diri. Aspek tersebut adalah aspek evaluasi penampilan (appearance evaluation). Hasil dari korelasi aspek evaluasi penampilan dengan harga diri yaitu $r=0,392$ dengan signifikansi seebesar 0,001 $(p<0,05)$. Evaluasi penampilan merupakan perasaan yang menunjukan puas atau tidak puas, menarik atau tidak menarik dengan penampilan diri sendiri. Hal ini menjelaskan bahwa siswi kelas X Pemasaran di SMK Negeri 1 Salatiga memiliki perasaan puas dengan penampilannya saat ini dan merasa bahwa penampilan dirinya menarik sehingga menumbuhkan harga diri tinggi pada siswi.

\section{PENUTUP}

Berdasarkan hasil penelitian diperoleh hasil: (1) Tidak ada hubungan yang signifikan antara citra tubuh dengan harga diri pada siswi kelas X Pemasaran SMK Negeri 1 Salatiga dengannilai $\mathrm{rxy}=0.157$ dengan koefisien signifikansi 0,155>0,05; (2) Setelah peneliti melakukan analisis lebih dalam terhadap aspek variabel citra tubuh dengan variabel harga diri maka hasil yang diperoleh adalah evaluasi penampilan (appearance evaluation) atau variabel X1 memiliki koefisien korelasi sebesar rxly $=0,392$ dengan signifikansi 0,001 $(\mathrm{p}<0,05)$, maka terdapat hubungan yang signifikan antara variabel citra tubuh aspek evaluasi penampilan dengan harga diri pada siswi kelas X di SMK Negeri 1 Salatiga; (3) Harga diri pada penelitian ini tergolong dalam ketegori sedang dan citra tubuh tergolong dalam kategori cukup tinggi.

Berdasarkan hasil peneitian ini, maka peneliti memberikan saran-saran sebagai berikut: (1) Siswi SMK Negeri 1 Salatiga yang telah memiliki harga diri tinggi hendakya tetap menjaga sikap positif terhadap dirinya dan selalu menampilkan penampilan yang baik. Seseorang yang mampu memberikan penghargaan yang tinggi atas dirinya maka akan memiliki harga diri tinggi. Karena seseorang yang telah memiliki harga diri tinggi maka apapun yang terjadi pada keadaan fisik tidak akan menurunkan harga dirinya; (2) Guru BK diharapkan dapat membantu siswi untuk terus memiliki sikap yang positif pada diri sendiri agar tetap memiliki harga diri yang tinggi melalui kegiatan dalam bimbingan dan konseling meskipun hasil penelitian tidak menunjukkan adanya hubungan antara citra tubuh dengan harga diri; (3) Keluarga diharapkan membantu menjaga dan meningkatkan dengan pemberian motivasi dan dukungan kepada anaknya terkait dengan sikap positif pada diri sendiri dan puas terhadap dirinya; (4) Bagi peneliti selanjutnya jika ingin melakukan penelitian dengan topik yang sama disarankan untuk mengggunakan aspek yang lain untuk mengukur harga diri remaja putri atau bisa dengan menambahkan variabel yang berbeda.

\section{REFERENSI}

Bell, Lorraine dan Rushfort, Jenny. (2008). Overcoming Body Image Distrubance: A Program for People with Eating Disorder. New York: Routledge.

Cash, F. Thomas. (2000). MBSRQ user's manual third edition. New York: Old Dominion University

Cash, T. F., \& Pruzinsky, T. (2002). Body image: A handbook of theory, research, and clinical practice. New York: The Guilford Press.

Dahlia. (2012). Hubungan Antara Body Image dan Self Esteem Pada Dewasa Awal Tuna Daksa.Calypta: Jurnal Ilmiah Mahasiswa Universitas Surabaya, 1, (1).

Fretes, Priskila D. (2014) Hubungan antara Citra Tubuh dengan Kepercayaan Diri Mahasiswi Papua Universitas Kristen Satya Wacana.Skripsi. Salatiga. UKSW

Hurlock, E. B. (1999). Psikologi Perkembangan: Suatu Pendekatan Sepanjang Rentang Kehidupan. Jakarta: Erlangga

Ilahi. Dian. (2014). HubunganAntara Citra Tubuh dengan Harga Diri Remaja Perempuan pada Komunitas Gym di Azkar Gym Masaran Sragen. Skripsi. Universitas Muhammadiyah Surakarta

Astri, Kharisma. (2002). The Secret To Be A Interesting Person. Klaten: Metafora.

Kitri. (2017). Hubungan Antra Citra Raga dengan Harga Diri pada remaja Awal di Madrasah Tsanawiyah Muhammadiyah 01 Malang. Nursing News 2 (2).

Mruk, C. J. (2006). Self Esteem research, theory, and practice: Toward a positive psychology of self esteem. New york: Springer Publishing Company.

Padmomartono, Sumardjono. (2014). Konseling Remaja. Yogyakarta: Penerbit Ombak.

Reber, Reber. (2010). Kamus Psikologi. Yogyakarta: Pustaka Pelajar

Ridha, Muhammad. 2012. Hubungan Antara Body Image dengan Penerimaan Diri pada Mahasiswa Aceh di Yogyakarta. Empathy 1 (1).

Santrock, John. W. (2007). Remaja Edisi Kesebelas. Jakarta: Erlangga

Setyaningsih, Catur. (2013). Hubungan antara Citra Tubuh (Body Image) dengan Penerimaan Diri pada Remaja Putri Kelas VIII di SMP N 6 Yogyakarta. Skripsi. Yogyakarta :Fakultas 
Shinta Widya Ratri, Tritjahjo Danny Soesilo, Setyorini Jurnal Bimbingan dan Konseling Ar-Rahman Volume 5, Nomor 1, Tahun 2019 e-ISSN 2477-6300

Ilmu Pendidikan Universitas Negeri Yogyakarta

Siti, Fathonatul dan Mutmainnah T. (2017). Perbedaan Self Esteem Ditinjau dari Tingkat Pendidikan pada Lulusan Diploma Tiga dan Sarjana. Prosiding Konferensi Nasional Peneliti Muda Psikologi Indonesia 2017, 2(1), Hal 57-63.

Soesilo, Tritjahjo Danny. 2018. Penelitian Inferensial dalam Bidang Pendidikan. Salatiga : Satya Wacana University Press.

Tafarodi, Milne. 2002. Decomposing Gloal SelfEsteem.Oxford: Journal of Personality 70(4)

Tsamarah, 2018. Hubungan Antara Citra Tubuh dengan Harga Diri Siswi SMA Kesatrian 2 Semarang. Jurnal Empati. 7(2).

Dipublikasikan Oleh : 